\title{
Venture capital and government involvement from a qualitative systematic literature review perspective
}

\author{
ERIKA JÁKI* (1) and ENDRE MIHÁLY MOLNÁR
}

Institute for the Development of Enterprises, Corvinus University of Budapest, Budapest, Fővám tér 8, H-1093 Hungary

Received: November 1, 2019 • Revised manuscript received: September 13, 2021 - Accepted: September 20, 2021

(C) 2021 The Author(s)

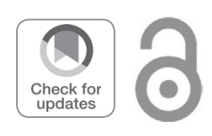

\begin{abstract}
The financing of young start-up companies is hindered by market failures that prompt governments around the world to intervene at the venture capital market. The aim of this paper is to give a comprehensive overview on this research field based on sound systematic literature review methodology, which was never done before. We found three major themes: pure governmental venture capital involvement, governmental-private venture capital cooperation, and governmental involvement in the financing of preseed startups. The evaluation of the governmental efforts varies according to these themes and also the investigated geographic location. Generally, pure governmental venture capital is the most controversial theme, the government-private cooperation is mostly viewed in a positive light, while the authors almost unanimously praise the government's efforts when financing pre-seed startups. We found that the success of governmental venture capital should not be judged based on the realized return of its investments, since profit maximalization is not its goal. The governments try to alleviate market failures at the venture capital market and transition financed startup companies to private financing. Thus, we advise researchers to use the number of this type of successful transitions as the success criteria of governmental investments.
\end{abstract}

\section{KEYWORDS}

venture capital, government, state, startup financing, GVC

\section{JEL CLASSIFICATION INDICES}

G31, G38, G24, L26

*Corresponding author. E-mail: erika.jaki@uni-corvinus.hu 


\section{INTRODUCTION}

The aim of the article is to give an overview on the governmental venture capital (GVC) research field from 2000 to 2018 by looking at the papers from the Scimago ranked journals. The issue is very relevant since economic growth can be fostered by the startup companies. The market failures present at the financing of the earliest lifecycle ("seed") stage startups (Kállay - Jáki 2019) combined with the positive externalities of startups, such as innovation, job creation and regional development spurred governments around the world to intervene at the early-stage startup financing market. Numerous GVC programmes were announced to support young companies and academic researchers were keen on investigating the reason and the efficiency of the governmental intervention. A qualitative systematic literature review presents the main findings of a group of articles that are relevant to the subject investigating the articles from different dimensions (Paré et al. 2015). Governmental involvement at the venture capital market has been the subject of two literature reviews so far (Callagher et al. 2015; Colombo et al. 2016) covering the period of 1988-2014. These literature reviews fall under the category of narrative reviews since they do not document the data collection and data analysis process and don't employ frequency counts.

Our systematic literature review of GVC is based on the articles published in the period of 2000-2018 from the Scimago ranked journals. Past research has generally addressed the questions of whether government involvement at this market is justified and whether government involvement is efficient. We provide a systematic categorization of current literature on the topic, by examining the topic through different lens to show how the answers to these questions can be so different.

\section{RESEARCH METHOD}

We performed our systematic data collection on 2018.10.31. using the following databases: Business Source Complete, Academic Search Complete, Business Source Premier, EconLit and ScienceDirect. First, we searched for the term 'venture capital' and either 'government' or 'state' in the title, abstract, or keywords of the published articles generating a list of 128 articles. Second, we narrowed the results to only peer-reviewed journal articles written in English and published in the journals ranked by Scimago getting a total of 74 unique articles. Examining the abstracts, we ended up with 29 relevant articles. Finally, we read through carefully all the articles and excluded three more papers identifying 26 relevant articles. We categorized the articles along multiple dimensions, such as year of publication, investigation period and geographical area, journals, editors, and the used methodology. Additionally, we identified a common thread that can be properly analyzed with qualitative content analysis. Every article contains some results about whether the government intervention is successful or not, and in what form. We captured these sentiments and categorized them.

Using an inductive approach to content analysis (Mayring 2004) we first did in vivo-coding, searching for thought-units in the form of words, parts of sentences, sentences or even multiple sentences that make up a coherent whole that are conclusions or observations about the investigated subject. We identified the thought-units in the abstract, introduction and conclusion parts of the articles. First, we categorized the in vivo-codes to the emerging categories. This 
categorizing process was done simultaneously by both authors, discussing the differences in opinions until a consensus was reached in each case of differing opinions which corresponds to Mayring (2004). After successfully linking every in vivo-code to a category, overarching themes and sub-themes were developed. As sub-themes, we assigned the relevant type of financing under examination to each category. The categories were further thematized by positive or negative remarks or recommendations on governmental intervention at the early-stage venture financing market.

\section{CLASSIFICATION AND ANALYSIS OF THE DATABASE}

Most of the papers investigating the governmental intervention at the VC market were published in 15 journals ranked Q1 or Q2 by Scimago. Four journals published more than one paper. Four and four papers were released in Journal of Business Venturing and Venture Capital journal, respectively. Five papers appeared in European Planning Studies and two were published in Research Policy. 16 out of the 26 articles were published in Q1 ranked journals and the rest in Q2 ranked journals. There were only one article published in Q3-Q4 Scimago ranked journals in the field of GVC between 2000-2018 (see Table 1).

\subsection{Databases and methodologies used in the articles}

The methodological approaches are quite varied within the field of GVC. Case studies (including comparative case studies) and econometric analyses are the most popular research methods featuring 8 and 10 articles within our database (see Table 2). The popularity of case studies can be explained, on the one hand, by the fact that certain authors are practical experts at the field drawing from their large local experience (Avnimelech et al. 2007; Avnimelech 2008; Cohen et al. 2012). On the other hand, data collection is especially difficult in this field, as Zangh (2014: 112) highlighted: "It is quite difficult for an outside researcher to acquire the original contracts and agreements, either from venture capital or from its investees, which describe the application of these mechanisms among them. Under such circumstances, only indirect proof of these incentive mechanisms can be obtained by conducting interviews and consulting secondary sources."

One of the major research streams is assessing the effectiveness of the governmental intervention for which the econometric analysis is the most suited method. The common approach of these articles is using a large, preferably international database of companies and building a model to test the effect of governmental investments choosing a proxy variable for the effectiveness of the investment. In these models the public investment is one of the explanatory variables and they test for whether it has a significant effect on the chosen effectiveness variable controlling for all other variables that can influence the response variable. It is thought-provoking that these articles come to different conclusions based on the kind of chosen effectiveness variable and the geographical source of their data. We also found one article that contained a theoretical model for governmental intervention. This approach is very rare in the field, most likely due to the interest being focused on empirical findings on the state's role. Only one article employed solely questionnaire analysis, this can be attributed to the fact that it is hard to get responses in this field from institutions. 
Table 1. Scimago ranking distribution of the research field

\begin{tabular}{|c|c|c|c|}
\hline Journal name & Year & \# of publications & Scimago ranking \\
\hline European Business Organization Law Review & 2014 & 1 & Q2 \\
\hline \multirow[t]{5}{*}{ European Planning Studies } & 2007 & \multirow[t]{5}{*}{5} & Q1 \\
\hline & 2008 & & Q1 \\
\hline & 2008 & & Q1 \\
\hline & 2017 & & Q1 \\
\hline & 2017 & & Q1 \\
\hline Global Economy Journal & 2014 & 1 & Q2 \\
\hline $\begin{array}{l}\text { International Journal of Economics and } \\
\text { Business }\end{array}$ & 2007 & 1 & Q2 \\
\hline Israel Affairs & 2012 & 1 & Q2 \\
\hline \multirow[t]{3}{*}{ Journal of Business Venturing } & 2007 & \multirow[t]{3}{*}{3} & Q1 \\
\hline & 2015 & & Q2 \\
\hline & 2016 & & Q1 \\
\hline Journal of Corporate Finance & 2017 & 1 & Q1 \\
\hline Journal of Commercial Biotechnology & 2011 & 1 & Q3 \\
\hline $\begin{array}{l}\text { Journal of High Technology Management } \\
\text { Research }\end{array}$ & 2011 & 1 & Q2 \\
\hline Journal of International Entrepreneurship & 2009 & 1 & Q2 \\
\hline Local Economy & 2015 & 1 & Q2 \\
\hline \multirow[t]{2}{*}{ Research Policy } & 2014 & \multirow[t]{2}{*}{2} & Q1 \\
\hline & 2018 & & Q1 \\
\hline Review of Finance & 2015 & 1 & Q1 \\
\hline Small Business Economics & 2018 & 1 & Q1 \\
\hline Technovation & 2016 & 1 & Q1 \\
\hline \multirow[t]{4}{*}{ Venture Capital } & 2005 & \multirow[t]{4}{*}{4} & Q2 \\
\hline & 2015 & & Q1 \\
\hline & 2015 & & Q1 \\
\hline & 2018 & & Q2 \\
\hline \multirow[t]{3}{*}{ Total } & & 15 & Q1 \\
\hline & & 10 & $\mathbf{Q 2}$ \\
\hline & & 1 & $\mathbf{Q 3}$ \\
\hline
\end{tabular}


Table 2. Used methodology in the articles

\begin{tabular}{|l|l|}
\hline Methodology & \multicolumn{1}{|c|}{ Articles employing it } \\
\hline General equilibrium model & Bauer - Burghof 2007 \\
\hline Case study & $\begin{array}{c}\text { Avnimelech 2008; Cohen et al. 2012; Zhang 2014; Gill } \\
\text { 2015; Wonglimpiyarat 2016 }\end{array}$ \\
\hline Comparative case study & $\begin{array}{l}\text { Heger et al. 2005; Avnimelech et al. 2007; Wonglimpiyarat } \\
\text { 2011; Baldock - Mason 2015 }\end{array}$ \\
\hline Questionnaire analysis & Frenkel et al. 2008; Bilau et al. 2017 \\
\hline Mixed research methods & Tucker et al. 2011; Wray 2015; Karsai 2018 \\
\hline Q methodology & Jung et al. 2017 \\
\hline Econometric analysis & $\begin{array}{l}\text { Cumming 2007; Cumming - Johan 2009; Herrera-Echeverri } \\
\text { et al. 2014; Standaert - Manigart 2018; Alperovych et al. } \\
2015 ; \text { Brander et al. 2015; Guerini - Quas 2016; } \\
\text { Cumming et al. 2017; Manigart 2018; Milosevic 2018 }\end{array}$ \\
\hline
\end{tabular}

17 out of the 26 articles used only secondary data to carry out their research. These were mainly quantitative data from publicly available databases, reports from research institutions, associations, committees or banks and studies made by other researchers. Considering the large number of econometric studies, it is not surprising that secondary data is so prevalent in this field.

\subsection{Relevance of the articles}

We identified two major research streams: the reason for government intervention and the effect of it (Fig. 1). Even though several reports and studies are written worldwide each year in this field, still only 26 articles were published in the Scimago Ranked journals between 2000 and 2018. Investigating why these papers were selected for publication is an interesting question for every researcher. We found that most of the articles possess high relevance because of a financial crisis investigating the market changes, and in that respect the government response to the crisis and/or the efficiency of the governmental intervention.

The dot-com crisis of 2000 heavily impacted the technological industry and the young technological start-ups, too. Heger et al. (2005) gave a historical overview between 1990-2005 of the UK and the German VC market and the role of the government. Frenkel et al. (2008) studied the Israeli VC market, as public technological incubators began operating in Israel in 2000 right after the dot-com crisis. Frenkel et al. highlighted the importance of the PTIP (Public Technological Incubator Programme) at the Israeli VC market. The paper of Avnimeelch (2008) is based on the same premise, but he focuses on the startup ecosystem as a whole and studies the innovation and technology policy in Israel. The motivation of Avnimelech et al. (2007) and Wonglimpiyarat (2016) is extended also by the success of the Israeli Yozma programme, while Cohen et al. (2012) deal primarily with the Office of the Chief Scientist programme.

After the beginning of the 2008 global financial crisis several authors phrase recommendations for the government of their investigated country, such as Wonglimpiyarat (2011) to the 


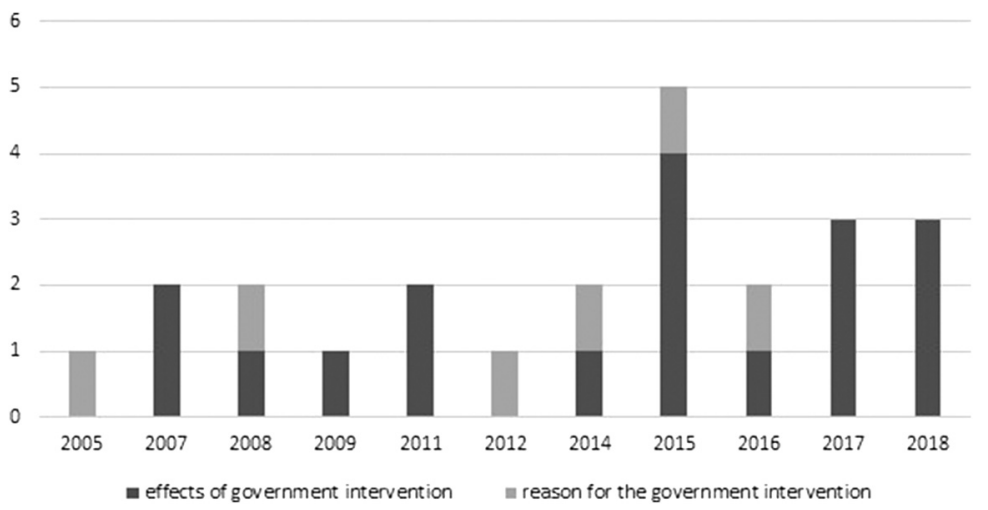

Fig. 1. Identified research streams over the years

Thai, Cohen et al. (2012) to the Israeli, Zhang (2014) to the Chinese and Gill (2015) to the British. A group of articles analyzed the governmental response to the crisis by various countries. Bilau et al. (2017) analyzed the governmental response in Portugal to the 2008 crisis focusing on the support of business angels, Baldock - Mason (2015) and Wray (2015) dealt with the UK response. The EU VC programmes provided the relevance to the articles of Karsai (2018) and Grilli - Murtinu (2014). The Australian GVC programmes inspired the work of Cumming and Johan (2009).

We also found two outliers. Bauer - Burghof (2007) investigated the government measures from a theoretical point of view. A merely theoretical basis forms the motivation for the article of Herrera-Echeverri et al. (2014) as well, since they want to uncover whether the neoclassical or Keynesian theories on governmental intervention are beneficial for the emerging markets when it comes to the health of the VC industry.

\subsection{Origin of the authors in relation to the investigated geographic area}

We found that 26 authors are form the group of European universities. Six of them are from the United Kingdom and five from the German or Italian universities. There are also authors from France, Belgium, Portugal, the Netherlands and Hungary. These researchers gave thorough analyses of the European VC market. 10 of them are researchers from Israel who introduced the motivations, methods and efficiency of the Israeli government. There were eight researchers from Canada, three from both Korea and the USA, two from both Thailand and Colombia, and finally, one form both Australia and China.

Nine out of the 26 articles were written in cooperation by researchers originating from different countries. Five out of the nine articles investigated the European market. Regarding the date of the publication, we found that the earliest article in our systematic literature review (Heger et al. 2005) was written by the European researchers from different countries investigating the public funds in the UK and Germany in cooperation with the Centre for European Economic Research and the University of Exeter. Jung et al. (2017) studied the south Korean VC market in a cooperation with the Seoul National University and the Southern Illinois University. Cumming - Johan (2009) investigated the VC market in Australia even though the authors are 
from Canada and the Netherlands. Two papers investigated worldwide trends (Herrera-Echeverri et al. 2014; Brander et al. 2015).

Comparing the origin of the authors' research institution (such as a university or an institute) and the investigated country - excluding articles written in an international cooperation - we found that they are equivalent except in five cases. Zhang (2014) from the Korea University Law School studied "the incentive mechanisms in the operation of Chinese domestic venture capital, [and] compared to American venture capital experience." (107 p.) Cumming (2007) from New York investigated the Australian VC market, meanwhile Wray (2015) from Australia investigated the North-East of England. Wonglimpiyarat (2016) form Thailand analyzed the Yozma programme in Israel. Wonglimpiyarat proposes that knowing this programme can be useful for other countries which aim to develop their high-tech startup ecosystem.

Figure 2 shows how the papers are distributed over their investigated geographic area. The majority of the articles only dealt with data from a single country. Most articles examined data only from the EU. The most popular countries under investigation were the UK and Israel. Among papers investigating the EU, five articles investigated several EU countries and four articles focused on one individual country such as France, Belgium, Germany or Portugal. On the other hand, several papers studied the Israeli market, some of them consider the Israeli Yozma programme to be an example worth following. A few of them investigated the Asian, Canadian and Australian markets. Herrera-Echeverri et al. (2014) investigated the effects of foreign direct investment, institutional quality and the size of the government on venture capital activity in the emerging markets. They concluded that governmental spending affects adversely the activities of the VC actors.

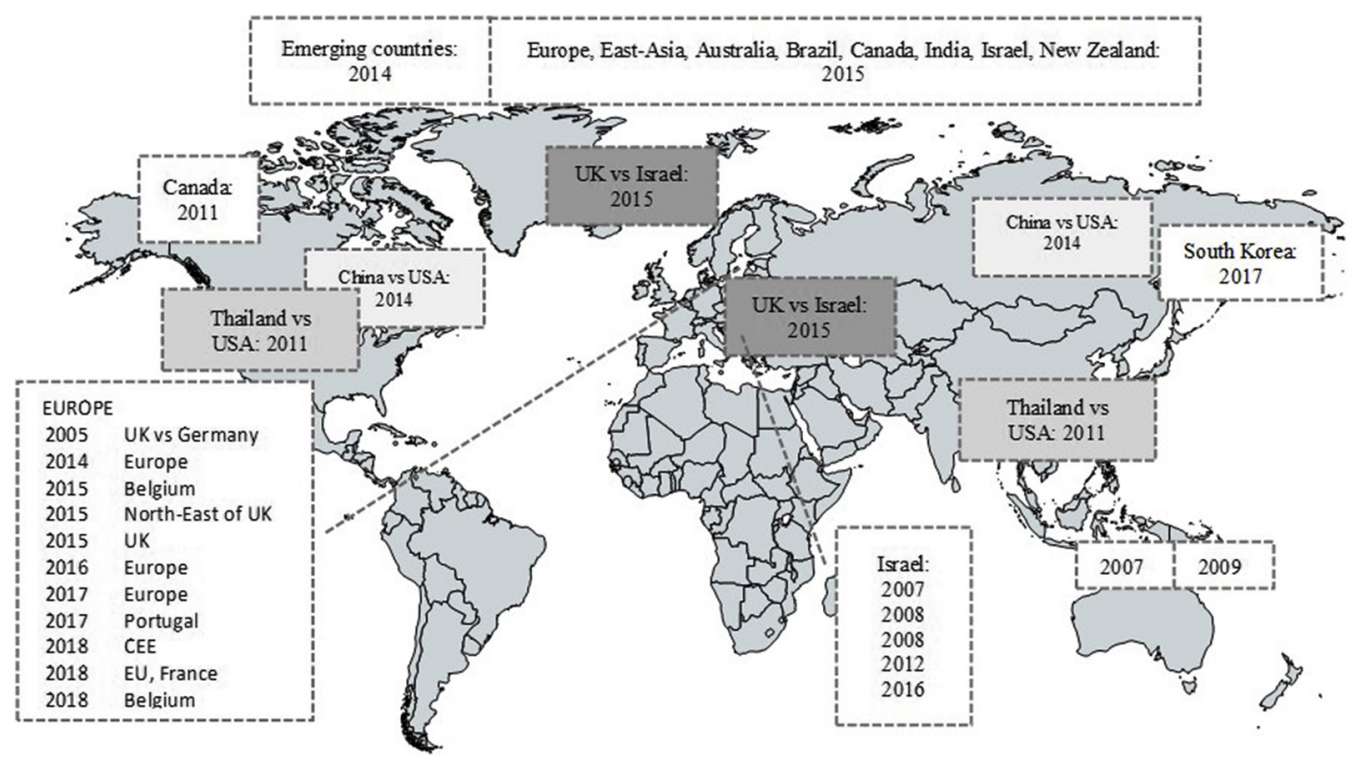

Fig. 2. Distribution of the articles over the investigated geographic area 
Based on Fig. 2, we can state that analyzing these articles can lead to a global overview on the main trends of governmental interventions at the VC market.

\subsection{Research questions according to the investigated geographic area and time period}

The papers differ from each other slightly in their research questions, meanwhile all of them are searching for the optimal level and way of the governmental intervention (Table 3).

3.4.1. Europe. Twelve articles studied the European region. The government's role in the early-stage capital investments in the UK was studied by several papers. The earliest publication in our database is Heger et al. (2005) who investigated the public funds in the UK and Germany between 1990 and 2005. Gill (2015) wanted to identify the key governmental measures required to rebuild the venture capital sector of the UK. He analyzed the UK government intervention historically between 1945-2014 and took into consideration the Israeli Yozma programme as an example worth following. The actuality of the investigation was the recent creation of the British Business Bank which received EU state-aid to promote early-stage risk capital. Baldock - Mason (2015) investigated also the efficiency of the UK governmental programmes between 2000-2014. Wray (2015) wanted to uncover how three processes unfolded in the UK in 2012: state rescaling, recessionary conditions and business support reforms.

It is an interesting question whether GVC-PVC partnership initiatives are proved to be effective or not, but there are different experiences from different geographical locations and the authors used different definition for success. Standaert et al. (2018) wanted to find out whether the government achieved its goal in Belgium through GVC-PVC partnership where the goal was defined as the employment growth of investee companies in the timeframe of October, 2005 to December, 2009. Karsai (2018) was interested in the quality of GVC-PVC programmes in the CEE region that were financed by the EU between 2007-2013.

A group of articles wanted to directly compare pure GVC and pure PVC financing in terms of effectiveness, but again, on different data sets and using different measures. Grilli - Murtinu (2014) wanted to compare GVC and PVC investments in the EU between 1994 and 2011 in terms of their effect on the sales and employment growth of target companies using the VICO database $^{1}$. A very similar study was done by Cumming et al. (2017) using the same dataset for the period of 1991-2010 but looking at the exit possibilities of the target companies. Still using the same dataset for the period of 1993-2010, Guerini - Quas (2016) placed the emphasis on the differences between GVC and PVC in terms of the target selection capabilities in the EU. Alperovych et al. (2015) defined success as productivity and compared the Belgian GVC and PVC investment targets between 1998-2007.

There are papers which investigated specific problems in a particular European country. Bilau et al. (2017) aimed to uncover whether business angels continue to invest during an economic crisis and how successful were policies of Portugal in promoting angel investing in the

\footnotetext{
${ }^{1}$ The database contains geographical, industry, investment and accounting information on companies which have received at least one venture capital or angel investment starting from 1/1/1998, operating in seven European countries (Belgium, Finland, France, Germany, Italy, Spain, and the United Kingdom) and Israel.
} 
Table 3. Investigated geographic area and time period

\begin{tabular}{|c|c|c|c|}
\hline & Reference & Investigated geographic area & $\begin{array}{l}\text { Investigated time } \\
\text { period }\end{array}$ \\
\hline \multirow[t]{12}{*}{ Europe } & Heger et al. (2005) & UK vs Germany & $1990-2005$ \\
\hline & Cumming et al. (2017) & $\begin{array}{l}\text { Belgium, Finland, France, Germany, } \\
\text { Italy, Spain, UK }\end{array}$ & 1991-2010 \\
\hline & Guerini - Quas (2016) & Europe & $1993-2010$ \\
\hline & Grilli - Murtinu (2014) & European Union & 1994-2011 \\
\hline & Alperovych et al. (2015) & Belgium & 1998-2007 \\
\hline & Milosevic (2018) & Europe, France & 2005-2013 \\
\hline & Karsai (2018) & CEE region & $2007-2013$ \\
\hline & Bilau et al. (2017) & Portugal & 2008-2012 \\
\hline & Standaert - Manigart (2018) & Belgium & 2005-2009 \\
\hline & Wray (2015) & North East of England & 2012 \\
\hline & Baldoc - Mason (2015) & UK & $2000-2014$ \\
\hline & Gill (2015) & UK vs Israel & $1945-2014$ \\
\hline \multirow[t]{5}{*}{ Israel } & Avnimelech (2008) & Israel & 1969-2005 \\
\hline & Frenkel et al. (2008) & Israel & 1990-2002 \\
\hline & Wonglimpiyarat (2016) & Israel & $1990-2012$ \\
\hline & Avnimelech et al. (2007) & Israel & 1991-2004 \\
\hline & Cohen et al. (2012) & Israel & 2000-2010 \\
\hline \multirow[t]{3}{*}{ Asia } & Jung et al. (2017) & South Korea & 2015 \\
\hline & Zhang (2014) & China vs USA & $1997-2010$ \\
\hline & Wonglimpiyarat (2011) & Thailand, USA & 2010 \\
\hline \multirow[t]{2}{*}{ Australia } & Cumming - Johan (2009) & Australia & $1982-2005$ \\
\hline & Cumming (2007) & Australia & $1982-2005$ \\
\hline Canada & Tucker et al. (2011) & Canada & 2001-2010 \\
\hline \multirow[t]{2}{*}{ Worldwide } & Brander et al. (2015) & Worldwide & 2000-2012 \\
\hline & $\begin{array}{l}\text { Herrera-Echeverri et al. } \\
\text { (2014) }\end{array}$ & Emerging countries & $1996-2010$ \\
\hline Theoretical & Bauer - Burghof (2007) & Theoretical paper & - \\
\hline
\end{tabular}


critical times of 2008-2012. Milosevic (2018) wanted to find out how social capital of the VC managers affects the success of the target companies. He focused on France and the timeframe was 2005-2013.

3.4.2. Israel. Six articles investigated the Israel venture capital market. Frenkel et al. (2008) studied the basic differences in characteristics between public and private technological incubators in Israel between 1990 and 2002. Cohen et al. (2012) assessed the Israeli OCS programmes and their evolution between 2000-2010, while Avnimelech (2008) presented the evolution of innovation and technology policy in the country between 1969 and 2005. Avnimelech et al. (2007) focused on the impact of VC and technological incubator support on the efficiency and development of the Israeli startups in the period of 1991-2004. Gill (2015) compared the structured risk venture activity of the UK Business Bank partly to the Israeli Yozma model, however without citing Frenkel et al. (2008) and Cohen et al. (2012) who introduced the Israeli VC market and government policy. Wonglimpiyarat (2016) also examined Israel between 1990-2012, particularly, how the governmental efforts helped shaping the ecosystem and VC industry. Based on these articles we get a broad overview form 1969 until 2010 of the Israeli government programmes promoting the VC industry which is accepted by the authors as a successful example. Gill (2015) considers the Israeli as a useful and successful model to be followed by the UK's government as well.

3.4.3. Asia. Three papers investigated the VC markets in Asian countries (China, South Korea and Thailand). Two papers compared the government measures. Zhang (2014) explores the Chinese corporate governance of SCLCs from the adaptive efficiency point of view between 1997 and 2010. He stated that the American model proved to be successful in fostering external innovation. Wonglimpiyarat (2011) examined Thailand's institutional setting, financial innovation system, innovation financing policies and technology financing mechanism effects on the innovation capacities, innovation outcomes, and the companies' abilities to pursue innovative ventures in 2010. He found that the US Silicon Valley model is an ideal institutional framework. He stated that the government should support the high-tech startups by providing financial incentives in the form of loans, equity, grants and tax subsidies. The third paper written by Jung et al. (2017) is focused on the different stakeholder perspectives surrounding the Centers for a Creative Economy and Innovation in South Korea in 2015. These three articles give us an insight into the VC market of three Asian countries and their specific problems regarding VC investments.

3.4.4. Australia. Two articles studied the Australian VC market. Similarly to the papers investigating the European market, these articles too pose the question of whether the GVC-PVC partnership initiatives are proved to be effective or not. Cumming (2007) aims to find out whether the GVC-PVC programme of Australia is proved to be successful compared to other VC funds. Cumming - Johan (2009) compared the success of an early-stage Australian GVCPVC programme with other governmental programmes. These two articles broaden our knowledge geographically about the effectiveness of the partnership between the public and the private sector promoting young entrepreneurs to succeed at the VC market. 
3.4.5. Canada, USA, worldwide. One paper examined the Canadian government and two papers have a broader geographic coverage. Tucker et al. (2011) were interested in finding out the structural problems that cause the life science sector to underperform in the otherwise well performing Canadian VC industry. The USA's VC model appeared in several papers as exemplary (Zhang 2014; Wonglimpiyarat 2011). Herrera-Echeverri et al. (2014) looked at how differently the macro variables and governmental intervention effect the level of $\mathrm{VC}$ activity in the emerging countries. Brander et al. (2015) examined the GVC and PVC investments on a worldwide dataset regarding the exit possibilities and Bauer - Burghof (2007) wrote a theoretical paper which does not concentrate on a specific geographical region.

\section{RESULTS OF THE CONTENT ANALYSIS}

We classified the in vivo-codes into main and sub themes that represent the type of governmental involvement. Along these main themes we separated the positive and negative evidences (Table 4).

\subsection{Pure GVC}

One of the most direct ways of intervening at the venture capital market by the government is to set up its own fund manager that manages the state provided funds. This is what we call pure GVC, as no private actors are involved in this type of financing. We found 24 in vivo-codes that represent the pure GVC in a positive way, and 24 in vivo-codes that represent it negatively. The debate is very heated on this form of governmental intervention and there is a great variance of results depending on the geographical area of the used database.

4.1.1. Positive evidence of pure GVC. 10 articles contain positive evidence out of the 19 articles analyzing the pure GVC intervention. The results of the pure GVC studies investigating the EU are mixed, while those from Israel, the USA, Thailand and South Korea are strictly positive.

There is a group of articles that found GVC to complement PVC investments. Cohen et al. (2012) highlighted that public funding of R\&D complements the private venture capital funding in the Israeli high-tech industry and Baldock - Mason (2015) have the same findings in the UK. Furthermore, they found that GVC stimulated the economy of the UK through employment

Table 4. Comparison of identified positive and negative evidences

\begin{tabular}{|l|c|c|}
\hline Theme & \# of positive evidence in vivo-codes & \# of negative evidence in vivo-codes \\
\hline GVC-PVC partnership & 17 & 12 \\
\hline $\begin{array}{l}\text { Government participation in the } \\
\text { pre-seed phase }\end{array}$ & 34 & 2 \\
\hline Pure government involvement & 24 & 24 \\
\hline Total & 75 & 38 \\
\hline
\end{tabular}


generation. Finally, Brander et al. (2015) found on an international dataset that the GVC funding increases the total amount of VC funding available to companies, thus there is no crowding-out effect. Brander et al. (2015) came to a different reason for the lack of crowding out effects investigating international data: many startups that receive GVC would not have received PVC at all so GVC fills the funding gap. Additionally, while the pure GVC investments have poor exit performance in the US, there is converse evidence in Europe. Finally, Karsai (2018) found that the shortage of private investors in the CEE region is the reason why the GVC investments do not crowd out PVC investments there.

Based on a theoretical analysis, Bauer - Burghof (2007) proved that the state intervention is most effective using scarce state money meanwhile mobilizing private capital, its role is essentially to promote getting PVC investment. Wonglimpiyarat (2016) also found that the GVC investments in Israel did not crowd out, but crowd in private investments. The study of Guerini Quas (2016) concluded, that since the GVC funding increases the likelihood receiving PVC, therefore GVC investors must be skilled at selecting target investments and certifying them to PVC investors through reducing informational asymmetry; thus, they found GVC to be efficient.

Governmental intervention can stimulate the economy and fill the funding gap of innovative projects on a short-term and long-term basis, specifically at the beginning of the innovation life cycle according to Wonglimpiyarat (2011) based on the investments at the US market. Jung et al. (2017) believed that the main role of GVC is to stimulate the development of the startup ecosystem of South Korea.

4.1.2. Negative evidence of pure GVC. There are two articles that found GVC to crowd out PVC. Only one made this claim based on empirical analysis. Using an emerging markets database, Herrera-Echeverri et al. (2014) found that government spending - including GVC has a negative effect on PVC activity, and the best way for the government to support the VC sector is to improve institutional quality and reduce spending. Bauer - Burghof (2007) built a theoretical model which indicated that large amounts of state intervention can crowed out private money.

A group of articles found agency problems associated with pure GVC in the EU and Australia. Karsai (2018) warned about the agency problems present in GVC financing in the CEE region and criticized the short timeframes, small fund sizes and restrictive administrative requirements of the GVC initiatives. Based on Australian data, Cumming - Johan (2009) also pointed out that that the Achilles heel of GVC programmes is the selection of the fund managers. Milosevic (2018) also found agency problems associated with GVC in France.

Furthermore, considerable international evidence indicates that GVC is less efficient than PVC. Tucker et al. (2011) cite the poor returns of the Canadian GVC investments as a reason to maintain only minimal government involvement and transition to mostly PVC funding. They also add that the Canadians GVC investments still helped to generate a critical mass of life science industry activity. Based on European data, the PVC investee companies have better exit opportunities than the GVC investees (Cumming et al. 2017). Also, Alperovych et al. (2015) found that the Belgian GVC investments have a significant negative impact on the productivity of the target companies. In the EU, GVC financing was unable to foster sales growth in the target companies because the GVC investors lack the value-added skills (Grilli - Murtinu 2014). Cumming - Johan (2009) also criticize the Australian GVC programmes for showing mixed 
performance associated with the provided financing and governance. Low exit performance was also cited as a sign of inefficiency by Brander et al. (2015), who found a negative association between exit performance and GVC funding in the USA. Standaert - Manigart (2018) found GVC investors to be worse at selecting prospective investments than PVC investors in Belgium; therefore, they suggested that GVC investors should let PVC investors select the target companies for them (GVC-PVC partnership), which would lead to more employment growth.

\subsection{GVC-PVC partnership}

There are two major ways the government can enter into a partnership with private actors providing financing to the startup companies. One way is to provide state funds that will be managed entirely by the private venture capital fund management (hybrid financing, indirect intervention). Even this type of partnership generally requires the PVC partner to provide a minor part of the managed funds. It is also possible for the state to affect the investment decision process by delegating managers to the fund management company to have some control over the kind of investments the fund will make. The other major way of GVC-PVC partnership is when a startup receives investments from both private and public venture capitalists at the same time (co-investment) or delayed. We found 17 positive and 12 negative evidences in the papers analyzing the GVC-PVC partnerships.

4.2.1. Positive evidences of GVC-PVC partnership. Several articles found that GVC complements PVC. Grilli - Murtinu (2014) examining EU data found that government involvement can have a positive impact on firm growth in a GVC-PVC partnership investment only if the private investor is the leading partner of the syndicate. They found the Australian co-investment model of Innovation Investment Fund (IIF) to be an effective approach. However, using worldwide international data, Brander et al. (2015) found that the presence of governmental investors in these partnerships can enhance the selection of the prospective portfolio companies compared to a pure PVC investment.

A group of articles found that investments made by this partnership have more positive impact on portfolio companies then either GVC or PVC investment. Standaert - Manigart (2018) observed this positive impact in Belgium as greater employment growth. Using EU data, Cumming et al. (2017) found this positive effect to be a greater likelihood of exit which is supported by Brander et al. (2015), who found based on an international dataset that the enterprises funded by GVC-PVC partnerships obtain more investment than purely GVC or PVC investees. Furthermore, they concluded that the governmental partner must also emphasize the financials when selecting portfolio companies rather than the externalities. Gill (2015) found that the government intervention advanced significantly in the UK regarding the so-called 'hybrid public-private' form. The improvement is observable in the design, targeting of the programmes and in the cost effectiveness of the local investments.

4.2.2. Negative evidences of GVC-PVC partnership. The GVC-PVC partnership programmes of the EU were criticized by Karsai (2018) for being over-engineered. She cited the long set-up times and insufficient fund sizes as the contributing factors. She also criticized the authorities in charge of the programmes for not enforcing the regulations on the participating fund managers 
and for not initiating thorough evaluations after the end of the programmes. Furthermore, in her opinion, the short timeframes of the programmes led to hasty investment decisions by the relatively inexperienced fund managers and to absorption pressure. Jung et al. (2017) also criticized the bureaucratic barriers in South Korea, which inhibit the effective cooperation between GVC and PVC investors. Gill (2015) found evidence of GVC-PVC inefficiency since mismatches between supply and demand still persist causing significant opportunity costs to the UK economy.

\subsection{GVC intervention at pre-seed financing}

The pre-seed phase presents a special case of startup financing, as these investments bear the highest amounts of risk due to the company possessing only an idea at this stage. The governments usually target this phase by providing financial support for incubators and business angels. Based on the content analysis, we found 34 thought-units with positive remarks on the government intervention and only two negative thought-units. Startups in the pre-seed phase lack any kind of track record, which makes investing in them much riskier than investing in the later stage startups. This drives the market failure of asymmetric information. Therefore, the government intervention can be justified the most in the pre-seed phase.

4.3.1. Positive evidences of GVC intervention at pre-seed financing. 6 out of the 26 authors gave positive remarks on the GVC intervention at the pre-seed financing phase. We classified them into 4 categories. Geographically, the positive comments originated from 5 different areas: Israel, Portugal, the EU, Australia and the UK.

The Israeli model regarding the public technological incubator programme became an example worth following by other countries as well. Between 1990 and 1993, the Israeli government established 28 incubators as a response to the wake of the large influx of immigrants providing the Israeli high-tech industry with highly skilled labour. One and a half decade later Frenkel et al. (2008) investigated whether there is still a need for the public intervention, or the private sector could take over its role. The authors emphasized that the private incubators cannot substitute fully for the public incubators. On the one hand, the public incubators sponsor a large variety of activities and provide a personal, intensive support system from the very early stage, unlike private incubators who concentrate in selected industries and cannot offer an intensive support system. On the other hand, the public technological incubator programme supports national objectives such as regional development and sponsor new immigrants in Israel. Furthermore, the government sponsors high-risk projects which are non-attractive for private investors or operating in sectors where private investors choose not to operate.

We found 8 positive remarks associated with the government financing of business angels or incubators. Public incubators ensure stability for long-term planning and supply a safe framework. Frenkel et al. (2008) also stated that there was a gap between supply and demand, so the government needed to intervene at different levels. In Portugal, the government places substantial emphasis on supporting the business angels to promote the early-stage startups. The government provides business angels with funding that can be spent through a co-investment scheme. The business angels in Portugal expressed that they prefer this type of governmental intervention (Bilau et al. 2017). Avnimelech et al. (2007) found that the venture capital backed 
companies, which priorly received support from governmental incubators, had significantly improved results over those, which did not. Cumming - Johan (2009) praised the Australian governmental pre-seed funds for being the primary provider of seed stage financing in the country.

One of the main advantages of public technological incubators is that they can support the VC industry. Frenkel et al. (2008) mentioned as a positive sign that public incubators support the immigrants in Israeli high-tech sector, for whom otherwise working there would not be feasible; the public incubators can also increase export and develop the periphery. The need for public incubators is justified by the fact that private investors won't invest in such a risky, early $\mathrm{R} \& \mathrm{D}$ stage company. Moreover, public incubators can encourage private investment in the fields in which it would not otherwise venture. Avnimelech et al. (2007) also pointed out that public technological incubators can have positive effects on the VC industry by reducing the drawbacks inherent in the VC sector.

Finally, some authors mentioned that governments promote innovation: Frenkel et al. (2008) stated that public incubators promote the knowledge transfer between the academy and industry, while helping a wide range of startupers in the high-tech industry to get the opportunity to work on their idea. Wonglimpiyarat (2016) found that the Israeli governmental programmes - such as the Yozma programme - along with the technological incubators and supporting university $\mathrm{R} \& \mathrm{D}$ projects played a major role in making the country a high-tech powerhouse.

4.3.2. Negative evidences of GVC intervention at pre-seed financing. Frenkel et al. (2008) set out numerous advantages for public incubators in Israel, meanwhile they also stated that in some domains the private incubators can better support the early-stage companies than public. This led to some VC funds preferring projects that are supported by private incubators than by public ones.

\subsection{Summary of the literature's recommendations}

We found 42 thought-units in 12 out of the 26 articles that formulate recommendations about how the government should intervene. There were recommendations associated with every geographic area under investigation. One of the most important recommendations was that the governments should complement private actors in the VC industry and under no circumstances compete with them. This suggestion appeared geographically in the UK (Gill 2015) and Thailand (Wonglimpiyarat 2011). Bauer - Burghof (2007) added that the state should only interfere in the case of an apparent market failure. Some industries depend more on state support such as private biotechnology incubators (Frenkel et al. 2008). The government participation should be limited to some fields and some specific locations, especially peripheral regions (Frenkel et al. 2008). Since the private sector possesses better business knowledge and vision, a cooperation between the private and public sector could be useful. Consequently, the public sector should not exit completely from the early-stage sector.

- GVC funds should not compete with each other. Investigating several countries such as Australia (Cumming - Johan 2009), Canada (Tucker et al. 2011), Thailand (Wonglimpiyarat 2011), the authors noticed that the government provides similar programmes and initiatives which compete with each other because separated governmental institutions and state 
authorities are following multiple goals and announcing overlapping programmes. Tucker et al. (2011) pointed out that multiple government funding agencies should merge to benefit from economies of scale.

- GVC should provide early- to late-stage investment. Long-term governmental financial support is in demand worldwide: Tucker (2011) in Canada; Gill (2015) in the UK, Wonglimpiyarat (2011) in Thailand and Cohen et al. (2012) in Israel.

- Governments need to apply incentives such as tax incentives and positive policy initiatives, comprehensive innovation financing programmes (Wonglimpiyarat 2011), fiscal incentives to encourage investments by reinvestment and tax relief (Bilau et al. 2017; Grilli - Murtinu 2014).

- Institutional quality can substitute for GVC. Herrera-Echeverri et al. (2014) used econometric methods on an emerging markets dataset and found that the VC investment activity was a positive function of institutional quality and a negative function of direct government involvement. They suggested focusing first on developing the governmental institutions leading to conditions for a thriving PVC ecosystem that requires only minimal GVC investment.

- Centralized measures cannot solve regional problems. The authors mentioned the peripheral problems of Israel, Germany and the UK. Heger et al. (2005) suggested that the regional involvement of the institutions could handle the regional allocation of the needed financial programmes. Avnimelech et al. (2007) also pointed out that governmental technological incubators were successful in attracting investments to the peripheral areas of Israel, even if their success rates are modest.

- The government's funds should be of sufficient scale. Gill (2015) in the UK and Wonglimpiyarat (2011) in Thailand accented that allocating sufficient resources can promote startups to become competitive. Wonglimpiyarat (2011) encourages the Thai government to support all types of startups.

- The government should focus on improving the efficiency of the investments. Bilau et al. (2017) based on their survey in Portugal suggested that the government should focus on educating the entrepreneurs rather than on organizing workshops and forums where financers and young companies can meet. Cohen et al. (2012) found the Israeli high-tech industry's dependence on foreign investors (mainly US) problematic therefore the government should try to remove the obstacles between Israeli institutional investors and the high-tech sector. Tucker et al. (2011) stressed that funds should not sponsor labour costs.

Our suggestion to governments is that they should create a comprehensive evaluation system for their intervention at the venture capital market which would not only measure the financial performance of the investments transparently but also their generated positive externalities. This would give a comprehensive view on the efficacy of the governmental involvement. This review should be performed regularly to evaluate the different ongoing governmental programmes.

\section{CONCLUSIONS AND RECOMMENDATION}

Between 2000 and 2018, 26 articles were published on state-supported VC in Q1-Q3 journals alone. We categorized these articles along several dimensions. The investigated geographic areas of these articles cover the USA, Canada, several countries from Europe, Israel, China, Thailand, 
South Korea and Australia. The investigated time periods range mainly from the early '90s up to 2014. We also explored in more detail the positive and negative evidences that these articles presented on the different forms of government intervention at the early-stage venture financing market using qualitative content analysis. We assigned categories and themes to the raw in vivocodes. Our identified themes correspond to the forms of involvement: pure governmental venture capital (GVC), governmental-private venture capital (GVC-PVC) partnership, governmental supported pre-seed financing and recommendations. The presented evidences varied with respect to the geographical location, the employed research method and the form of intervention. Pure GVC was found to not crowd-out PVC in the studies using European data, but the opposite was found when examining the emerging markets. Pure GVC investments were found to be less efficient than PVC investments in several geographic locations. On the other hand, GVC-PVC partnership is praised by most articles for making better investments than pure GVC or PVC alone. The CEE GVC-PVC programmes, however, were criticized for being too short, small in scale and bureaucratical. Governmental pre-seed support through technological incubators was found to support the VC industry and advance national objectives in Israel. Even though the private technological incubators were found to provide better services, they can't substitute for public incubators as they support a far greater range of startups than do the private ones. There is also evidence of successful governmental efforts to support business angel funding in Portugal.

Based on the papers, we identified 11 categories of recommendations made by the authors. The most frequent suggestion was that the government should complement the private sector and not compete with it. This recommendation has a very significant consequence to further research since the state could not realize a fair return on their investment funds and it is principally wrong to compare its performance with the private sector. Otherwise, when the realized return is lower than the private investors', governmental agents are blamed for handling the state provided sources carelessly. But even if they perform better than the private investors, they can still be blamed for crowding out the private investors. Thus, the governments should provide the startupers with the opportunity to do $\mathrm{R} \& \mathrm{D}$, and then, transfer the company to be funded by private investors as early as possible. Consequently, the state efficiency should be measured by the number of those projects which were bought out by the private sector. Another important global suggestion is that the programmes announced by the government should complement each other. As a summary, governments should intervene at the very risky pre-seed phase by funding projects and educate the entrepreneurs. Furthermore, governments should ensure a stable institutional background which can also lessen the need for governmental intervention.

This article provides valuable insight for policymakers and venture capitalists who aim to understand the international evidences of GVC intervention better. We hope that it will also spark new research in the field focusing on more appropriate success criteria for GVC initiatives, which would increase the added value of the research field as a whole.

\section{ACKNOWLEDGMENTS}

The research was funded by EFOP-3.6.3.-VEKOP-16-2017-00007 "Young researchers from talented students - Fostering scientific careers in higher education". 


\section{REFERENCES}

Alperovych, Y. - Hübner, G. - Lobet, F. (2015): How Does Governmental Versus Private Venture Capital Backing Affect a Firm's Efficiency? Evidence from Belgium. Journal of Business Venturing, 30(4): 508-525. Avnimelech, G. (2008): A Five-Phase Entrepreneurial Oriented Innovation and Technology Policy Profile: The Israeli Experience. European Planning Studies, 16(1): 81-98.

Avnimelech, G. - Schwartz, D. - Bar-El, R. (2007): Entrepreneurial High-tech Cluster Development: Israel's Experience with Venture Capital and Technological Incubators. European Planning Studies, 15(9): 1181-1198.

Baldock, R. - Mason, C. (2015): Establishing a New UK Finance Escalator for Innovative SMEs: The Roles of the Enterprise Capital Funds and Angel Co-Investment Fund. Venture Capital, 17(1-2): 59-86.

Bauer, E. - Burghof, H. P. (2007): The Economics of State Subsidies in Early-Stage Financing. International Journal of the Economics of Business, 14(3): 433-457.

Bilau, J. - Mason, C. - Botelho, T. - Sarkar, S. (2017): Angel Investing in an Austerity Economy - The Take-Up of Government Policies in Portugal. European Planning Studies, 25(9): 1516-1537.

Brander, J. A. - Du, Q. - Hellmann, T. (2015): The Effects of Government-Sponsored Venture Capital: International Evidence. Review of Finance, 19(2): 571-618.

Callagher, L. J. - Smith, P. - Ruscoe, S. (2015): Government Roles in Venture Capital Development: A Review of Current Literature. Journal of Entrepreneurship and Public Policy, 4(3): 367-391.

Cohen, E. - Gabbay, J. - Schiffman, D. (2012): The Office of the Chief Scientist and the Financing of HighTech Research and Development, 2000-2010. Israel Affairs, 18(2): 286-306.

Colombo, M. G. - Cumming, D. J. - Vismara, S. (2016): Governmental Venture Capital for Innovative Young Firms. The Journal of Technology Transfer, 41(1): 10-24.

Cumming, D. (2007): Government Policy Towards Entrepreneurial Finance: Innovation Investment Funds. Journal of Business Venturing, 22(2): 193-235.

Cumming, D. - Johan, S. (2009): Pre-Seed Government Venture Capital Funds. Journal of International Entrepreneurship, 7(1): 26-56.

Cumming, D. J. - Grilli, L. - Murtinu, S. (2017): Governmental and Independent Venture Capital Investments in Europe: A Firm-Level Performance Analysis. Journal of Corporate Finance, 42: 439-459.

Frenkel, A. - Shefer, D. - Miller, M. (2008): Public versus Private Technological Incubator Programmes: Privatizing the Technological Incubators in Israel. European Planning Studies, 16(2): 189-210.

Gill, D. E. (2015): Consolidating the Gains. Venture Capital, 17(1-2): 43-58.

Grilli, L. - Murtinu, S. (2014): Government, Venture Capital and the Growth of European High-Tech Entrepreneurial Firms. Research Policy, 43(9): 1523-1543.

Guerini, M. - Quas, A. (2016): Governmental Venture Capital in Europe: Screening and Certification. Journal of Business Venturing, 31(2): 175-195.

Heger, D. - Fier, A. - Murray, G. (2005): Review Essay: Regional Venture Capital Policy: UK and Germany Compared. Venture Capital, 7(4): 373-383.

Herrera-Echeverri, H. - Haar, J. - Estevez-Bretón, J. B. (2014): Foreign Investment, Institutional Quality, Public Expenditure, and Activity of Venture Capital Funds. Emerging Market Countries, 14(2): 127162.

Jung, K. - Eun, J.-H. - Lee, S.-H. (2017): Exploring Competing Perspectives on Government-Driven Entrepreneurial Ecosystems: Lessons from Centres for Creative Economy and Innovation (CCEI) of South Korea. European Planning Studies, 25(5): 827-847. 
Kállay, L. - Jáki, E. (2019): The Impact of State Intervention on the Hungarian Venture Capital Market. Economic Research - Ekonomska Istraživanja, 33(1): 1130-1145.

Karsai, J. (2018): Government Venture Capital in Central and Eastern Europe. Venture Capital, 20(1): 73102.

Mayring, P. (2004): Qualitative Content Analysis. In: Flick, U. - von Kardoff, E. - Steinke, I. (eds): A Companion to Qualitative Research. London: SAGE, pp. 159-176.

Milosevic, M. (2018): Skills or Networks? Success and Fundraising Determinants in a Low Performing Venture Capital Market. Research Policy, 47(1): 49-60.

Paré, G. - Trudel, M.-C. - Jaana, M. - Kitsiou, S. (2015): Synthesizing Information Systems Knowledge: A Typology of Literature Reviews. Information \& Management, 52(2): 183-199.

Standaert, T. - Manigart, S. (2018): Government as Fund-of-Fund and VC Fund Sponsors: Effect on Employment in Portfolio Companies. Small Business Economics, 50(2): 357-373.

Tucker, J. - Chakma, J. - Fedak, P. W. M. - Cimini, M. (2011): Catalyzing Capital for Canada's Life Sciences Industry. Journal of Commercial Biotechnology, 17(4): 330-348.

Wonglimpiyarat, J. (2011): The Dynamics of Financial Innovation System. The Journal of High Technology Management Research, 22(1): 36-46.

Wonglimpiyarat, J. (2016): Government Policies Towards Israel's High-Tech Powerhouse. Technovation, 52: $18-27$.

Wray, F. (2015): Venture Capital and Investor Readiness in a Post-Crisis and State-Rescaling Context: Revisiting the North East of England. Local Economy, 30(4): 389-404.

Zhang, L. (2014): Corporate Governance of Chinese State-Controlled Listed Companies: A Revisit through the Lens of Venture Capital. European Business Organization Law Review, 15(1): 107-139.

Open Access. This is an open-access article distributed under the terms of the Creative Commons Attribution 4.0 International License (https://creativecommons.org/licenses/by/4.0/), which permits unrestricted use, distribution, and reproduction in any medium, provided the original author and source are credited, a link to the CC License is provided, and changes - if any - are indicated. (SID_1) 